Annales Geophysicae (2003) 21: 103-121 (C) European Geosciences Union 2003

(6)

\title{
Near Real Time SLA and SST products during 2-years of MFS pilot project: processing, analysis of the variability and of the coupled patterns
}

\author{
B. Buongiorno Nardelli ${ }^{1}$, G. Larnicol ${ }^{2}$, E. D'Acunzo ${ }^{1}$, R. Santoleri ${ }^{1}$, S. Marullo ${ }^{3}$, and P. Y. Le Traon ${ }^{2}$ \\ ${ }^{1}$ Istituto di Fisica dell'Atmosfera, CNR, Roma, Italy \\ ${ }^{2}$ Collecte Localisation Satellites, Toulouse, France \\ ${ }^{3}$ Ente Nazionale per l'Energia e l'Ambiente, Roma, Italy
}

Received: 23 August 2001 - Revised: 6 May 2002 - Accepted: 4 June 2002

\begin{abstract}
The Near Real Time (NRT) operational products developed from satellite data (AVHRR, Topex/Poseidon, Ers-2) in the framework of the Mediterranean Forecasting System Pilot Project (MFSPP, autumn 1998-autumn 2000) are described and compared to delayed time products over the Mediterranean sea. MFSPP SLA and SST data are then discussed in the general context of the Mediterranean circulation, showing the interannual variability of the fields and identifying recurrent or anomalous features at mesoscale/sub-basin scales. Finally, MFSPP data are used to test, on a regional (Mediterranean) context, a multi-variate method to identify coupled modes of variability, consisting in the SVD of the covariance between SST and SLA.
\end{abstract}

Key words. Oceonography: general (marginal and semiclosed seas) - Oceonography: physical (sea level variations; upper ocean processes)

\section{Introduction}

In the framework of the Mediterranean Forecasting System Pilot Project (MFSPP), a near real time acquisition and processing system of remote sensing data was set up and tested for the Mediterranean sea. The system was based on existing facilities and could also serve as a prototype for future operational systems. Near real time (NRT) remote sensing data provided unique data sets for the setting up of the operational Mediterranean Forecasting System, being used for the initialization of the weekly forecasts. The development and test of algorithms to process NRT altimeter data, the development of a NRT Sea Surface Temperature product, and the analysis of the remotely sensed data collected during MFSPP were thus fundamental steps in the definition of an operational satellite system.

In developing ocean forecasting systems, it is important to establish the reliability and accuracy of the data used. As

Correspondence to: B. Buongiorno Nardelli

(bruno@ekman.ifa.rm.cnr.it) a consequence, the aim of this paper is, first of all, to describe the MFSPP near real time satellite data set (AVHRR, TOPEX/Poseidon and ERS-2) and to quantify the quality of NRT products against advanced products, obtainable only in delayed time. Secondly, a scientific analysis of the data will be performed in order to set the dynamical context of the MFSPP period with respect to the "typical" patterns found in the Mediterranean. This analysis will be carried out with the objective of defining the MFSPP period as "climatological" or characterized by anomalous patterns and as support to the interpretation of modelling results.

Finally, a method for the identification of the coupled patterns in SST and SLA will be tested and applied to the first two years of MFSPP. In fact, altimeter derived SSH (Sea Surface Height) and SST (Sea Surface Temperature) obtained from AVHRR, have already proved to be quite useful to evaluate the sea surface variability (for the Mediterranean Sea, see for example: Larnicol et al., 1995; Iudicone et al., 1998; and Marullo et al., 1999), but can also be thought as useful tools to investigate the ocean dynamics and atmosphereocean interactions.

In accordance with this strategy, in the last years many studies investigated the relation between SSH and heat storage rates, from altimeter measurements and in situ data (see e.g. Wang and Koblinsky, 1997; Stammer, 1997; Chambers et al., 1997; and Vivier et al., 1999). Stammer (1997) examined the response of the sea surface topography to the heat flux and wind-stress on the large scale, while Chambers et al. (1997) estimated the ocean heat storage rates and heat fluxes on the global scale from 3 years of TOPEX/Poseidon (T/P) altimeter data. This is of particular interest, as the comparison between the SST data from AVHRR and the SSH from $\mathrm{T} / \mathrm{P}$ and ERS altimeters could, in principle, give us some information on the depth of the mixed layer itself.

However, the comparison of a vast and complex amount of data such as this obtained from AVHRR sensors and satellite altimeters is not trivial, and even if different objective methods have been introduced up to now to try to give a synthetic interpretation of the data, not all of them would 
give significant results. The most common methods of analysis are based on EOFs of single fields, which describe the field as a sum of modes that explain the variability of the field. The majority of the modes explain a very low percentage of the variance and consequently the analysis can be reduced to only a few significant modes (Fukomori and Wunsch, 1991). On the other hand, EOFs are not necessarily related to physical processes, as the modes and expansion coefficients could simply be mathematical artifacts due to the method of decomposition. In this sense, the comparison of different datasets represents a fundamental tool to understand the physical significance of a particular EOF. In spite of this, if we analyse multiple fields separately, it could be difficult to recognize related modes. In this context, the approach proposed by Leuliette and Wahr (1999), coupling the variability in SSH and SST seems particularly interesting. Actually, the two years of MFSPP satellite data are not the ideal dataset to perform an advanced analysis of the coupled patterns, as a longer time period would allow the identification of signals on longer scales, which are clearly more interesting from a climatological point of view. In fact, the signals that can be detected by this analysis obviously lie within a range of frequency that is limited by the sampling of the satellite altimeters and by the length of the time series.

However, MFSPP data represent a perfect set to test on a regional (Mediterranean) context a methodology that up to now was applied only to global scale datasets. A multivariate method consisting in the SVD of the covariance between SST and SSH (Leuliette and Wahr, 1999) was thus applied to MFSPP in order to identify the coupled modes of variability in the Mediterranean Sea.

The paper is organized as follows: in Sect. 2 the NRT processing system is presented; the accuracy of NRT products is described in Sect. 3; Sect. 4 is devoted to the analysis of SLA and SST variability in the two MFSPP years, discussing the general circulation of the Mediterranean sea; the Coupled Pattern Analysis (CPA) algorithm is presented in Sect. 5, while the results of the CPA applied to the MFSPP data are discussed in Sect. 6. Conclusions are presented in Sect. 7.

\section{Near Real Time (NRT) processing of satellite data during MFSPP}

The altimeter NRT processing system adopted during MFSPP is based on the CLS global altimeter data acquisition module developed as part of the DUACS (Developing Use of Altimetry for Climate Studies) project. The acquisition system works on a continuous mode and receives data from several centres (ERS-2 Fast Delivery Products (FDP) from the GTS system, ERS-2 orbit field computed by the Delf University, Topex Navocean Interim Geophysical Data Record (IGDR), Poseidon IGDR, and the ECMWF meteorological field). When all data are available, it automatically generates level 2 data, which correspond to the acquired raw data. After the acquisition step, the usual geophysical corrections are applied (wet and dry tropospheric, ionospheric, electromag- netic, tides, inverse barometer; see Le Traon and Ogor (1998) for details). Despite the accuracy in the determination of the orbit is quite satisfying for T/P and similar for IGDR and GDR (4 and $2 \mathrm{~cm} \mathrm{rms,} \mathrm{respectively),} \mathrm{the} \mathrm{one} \mathrm{of} \mathrm{ERS-2,} \mathrm{that}$ is derived from JGM-3 orbit 2, presents a large error $(6 \mathrm{~cm}$ minimum). Another source of differences for ERS-2 data is the wet tropospheric correction, that derives from ECMWF model fields for FDPs while the Ocean PRoducts (OPRs) use the correction derived from the on-board radiometer.

The next step in the processing, i.e. the merging of multiple altimeters' data, requires homogeneous and intercalibrated SSH data sets. These are obtained by performing a global crossover adjustment of the ERS-1/2 orbits, using the more precise T/P data as a reference (Le Traon and Ogor, 1998). The data are finally resampled every $7 \mathrm{~km}$ along the tracks using cubic spline interpolation.

In order to eliminate geoid signals, Sea Level Anomalies (SLA) are constructed by removing a 5-year mean (19931997) from surface heights. To reduce measurement noise, the SLA are filtered with a $35-\mathrm{km}$ median filter and a Lanczos filter with a cut-off wavelength of $42 \mathrm{~km}$. The data are then sub-sampled one point in two. Combined T/P and ERS-2 SLA maps were produced each week on the regular $1 / 8^{\circ} \times 1 / 8^{\circ}$ grid of the MFSPP model by using a sub-optimal space/time optimal interpolation (Bretherton et al., 1976).

Despite the global crossover adjustment of the ERS-2 tracks, the merging of T/P and ERS data is not trivial, as some residual large wavelength errors still remain, especially in the NRT data. In order to remove those along-track biases, mainly induced by orbit errors and inaccurate inverse barometer correction (Le Traon and Gauzelin, 1997), we have applied an improved mapping method based on multi-satellite altimeter data developed by Le Traon et al. (1998). Its principle is to take directly into account the along-track long wavelength error by modifying the a priori error covariance prescribed in the optimal interpolation method. More specifically, our analysis was performed using space and time correlation functions with a $120-\mathrm{km}$ and 15 -day zero crossing. This choice for the space and time correlation radius corresponds to the scales sampled by the altimeter data rather than to the typical Mediterranean mesoscale. Measurement noise was set to $2 \mathrm{~cm}$ for T/P and $3 \mathrm{~cm}$ for ERS-1/2, and large wavelength errors to $3 \mathrm{~cm}$ for T/P and $4 \mathrm{~cm}$ for ERS-1/2.

The processing of AVHRR NRT data begins with the reception of the raw telemetry stream by the IFA (Istituto di Fisica dell' Atmosfera) for the eastern Mediterranean images, and by the CMS (Centre de Meteorologie Spatiale) for the western Mediterranean images. The HRPT stations acquire AVHRR data 5 to 6 times per day per satellite over the areas of interest. During the first two years of MFSPP (starting from October 1998) more than 2500 passes covering portions of the Mediterranean sea were received mainly from NOAA-14 and for limited periods (when there were some problems of noise on the frequencies dedicated to NOAA-14 transmission at IFA) from NOAA-12 or NOAA-15 satellites. During this limited periods NOAA-12 and NOAA-15 data were adjusted to NOAA-14 to eliminate the existing bias. 
Only NOAA-14 passes were acquired after June 1999. The data were preliminary processed at ENEA/IFA and CMS using apposite software designed to ingest, navigate and extract the geophysical parameters from the raw data (DSP software developed at Miami University for ENEA/IFA). The SST was then computed from the brightness temperature of channel 4 and 5 of the AVHRR through the linear MCSST algorithm proposed by MacClain et al. (1985) at IFA and using a non linear algorithm at CMS, as described for example in Brisson et al. (1998). A wide overlapping area was kept in both CMS and IFA data, in order to check and eventually eliminate biases between western and eastern Mediterranean sub-products (see also the MFSPP first year report, http://www.cineca.it/ mfspp000/ documents/DATA/MasterScientReport.pdf). Since SST calculation from infrared measurements is affected by the presence of clouds, a proper cloud detection algorithm has been developed and applied to the images. The algorithm is based on the different statistical (variance) and physical characteristics (spatial gradients) of clouds and sea surface temperatures. However, any automatic declouding procedure can fail in the presence of strong oceanic fronts or thin stratiform clouds. As a consequence, a visual control and further elimination of cloudy pixels from the declouded images has been applied. Once the declouded images were obtained, daily maps were created composing single pass images. In order to avoid the diurnal cycle and the skin heating effects, only night passes have been used.

After composing the images, daily maps were binned at $1 / 8^{\circ}$ over the grid of MFSPP model. The binning procedure consists of a median filter with a window of $1 / 8^{\circ}$ centred on the model grid points. The use of a median filter instead of a simple average was decided in order to remove residual outliers. The model sea-land mask was applied at this step. Daily SST data were then weekly averaged in NRT mode and data voids were filled using an optimal interpolation algorithm (same as Marullo et al., 1999) to obtain weekly maps. At this stage maps were made available to MFSPP authorized users (each Thursday before 12:00 LT during MFSPP). During the TOP phase of the project also daily images in .hdf and .gif format were made available and distributed on the web.

\section{Accuracy of NRT satellite data during MFSPP}

In the framework of MFSPP, weekly maps of combined T/P and ERS-2 and of SST from AVHRR sensors were operationally produced in NRT mode. These data were used to monitor the Mediterranean circulation and were assimilated in the general circulation model. As a consequence, a first fundamental step before further analyses can be done is to evaluate the accuracy of this product with respect to delayed time data.

On one hand the DUACS NRT processing had already started since January 1998, which allowed us to reprocess all the altimeter data from 1998, and to evaluate the accuracy of the altimeter NRT MFSPP system. The DT data used were distributed by AVISO (MGC-B, version 2, AVISO, 1996) for the M-GDRS and by the French Processing and Archiving Facility (PAF) CERSAT for the OPRs (see Larnicol et al., 2002, for more details). The DT processing (calibration, validation, calculation of SLA) is the same than in the NRT case. However, the main differences with the NRT data are the orbit error, the wet tropospheric corrections, and obviously the minor coverage.

On the other hand, National Aeronautics and Space Administration (NASA) Pathfinder global SST dataset (version 4.1, until 31 December 1999) has recently become available at $9 \mathrm{~km}$ resolution at the Physical Oceanography Distributed Active Archive Center (PODAAC) (for more information see also http://www.podaac.jpl.nasa.gov/sst/). The Pathfinder program reprocessed all AVHRR data from 1985 to 1999 under a single algorithm to enable a consistent use of SST in climate studies (Kearns et al., 2000). The Pathfinder algorithm relies on coefficients derived from co-located, cotemporal satellite and in situ SST observations ("matchups"). Coefficients are estimated on a monthly basis, and for two separate atmospheric regimes (dry and medium to moist atmospheres). Pathfinder SST should be corrected by the worldwide mean bulk to skin difference that, at low and mid latitude, is $0.12^{\circ} \mathrm{C}$ (Kearns et al., 2000). Recent ocean observations made at low and middle latitudes found a bias of only $0.07 \pm 0.31^{\circ} \mathrm{C}$ between Pathfinder estimate and accurate in situ skin temperature measurements (Kearns et al., 2000). For what concerns the Mediterranean sea, a validation of Pathfinder SST night-time data with simultaneous bulk temperatures obtained from the MEDATLAS CTD data set gave a mean bias error (CTD-Pathfinder) of $0.2^{\circ} \mathrm{C}$ (D'Ortenzio et al., 2000). This means that in this basin the mean bulk to skin bias is still present but attains very small values. These data have been interpolated here using the same scheme as in Marullo et al. (1999a) and then weekly averaged and resampled in MFSPP format.

The validation consists in the characterisation of the differences between the $1 / 8^{\circ} \times 1 / 8^{\circ}$ maps calculated with Pathfinder delayed time data (DT) and MFSPP NRT data. The mean error associated with the NRT system could be estimated by calculating the mean bias error and the average for all the grid points of the rms of the differences between NRT and DT data.

\subsection{SLA}

For what concerns altimeter data, the average rms of the difference is around $3.76 \mathrm{~cm}$ for combined T/PERS maps and $3.21 \mathrm{~cm}$ for maps computed from T/P alone (Table 1), and finally represents a non-negligible part of the mean variance of SLA (comprised between 6 to $9 \mathrm{~cm}$ ). More precisely, Figure 1, which represents the spatial structure of the error, reveals that it is weaker along the T/P tracks. Indeed, it ranges between $2 \mathrm{~cm}$ to $3 \mathrm{~cm}$, whereas the error can reach values of about $5 \mathrm{~cm}$ between the T/P tracks. This means that the NRT ERS data (FDP) are less accurate than the NRT T/P data (IGDR). The main sources of the differences between the DT 

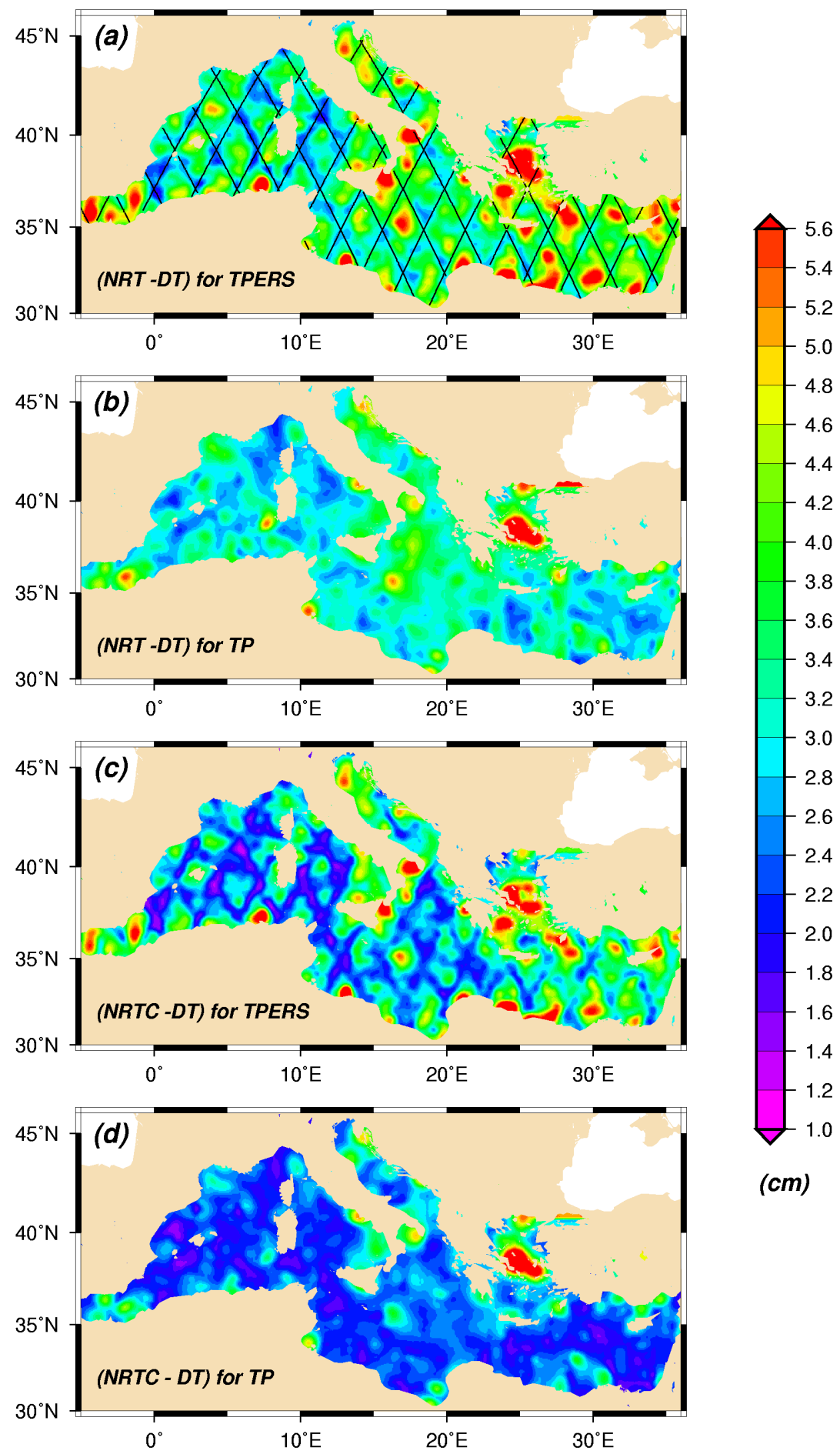

5.0

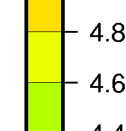


Table 1. RMS of the differences between NRT and delayed time altimeter maps. The column with RMS at $\mathrm{T}_{0^{-}}-7$ days corresponds to the actual NRT MFSPP system. The column at $\mathrm{T}_{0}-14$ days stresses the problem of the shift in the observation period

\begin{tabular}{lll}
\hline & $\begin{array}{l}\mathrm{RMS} \\
\mathrm{T}_{0}-7\end{array}$ & $\begin{array}{l}\mathrm{RMS} \\
\mathrm{T}_{0}-14\end{array}$ \\
\hline $\begin{array}{l}\text { annual } \\
\text { T/PERS }\end{array}$ & 3.76 & 3.30 \\
\hline $\mathrm{T} / \mathrm{P}$ & 3.21 & 2.49 \\
\hline winter & & 3.43 \\
T/PERS & 4.00 & 2.83 \\
\hline T/P & 3.66 & \\
\hline summer & & 3.17 \\
T/PERS & 3.36 & 2.15 \\
\hline T/P & 2.53 & \\
\hline
\end{tabular}

(Fig. 1). The less dense space-time data coverage has two origins. The first one is the lower quality of the NRT time data, that implies more rejections during the validation. The second one is the NRT system itself. In fact, as the temporal correlation radius is 15 days, almost 4 weeks of data are used to calculate the DT maps. On the contrary for the NRT system, only 3 weeks of observations (the two weeks before and only one week after the date of the map) are used, in order to have only one week of delay ( $\mathrm{T}_{0}-7$ days). To quantify the effect of the different temporal windows adopted for the interpolation, NRT maps were calculated with a delay of 14 days $\left(\mathrm{T}_{0}-14\right)$ for the same period (i.e. 1998). The results are listed in the second column of the Table 1, and show an improvement of $1.8 \mathrm{~cm}$ and $2 \mathrm{~cm} \mathrm{rms} \mathrm{for} \mathrm{combined} \mathrm{(T/PERS)} \mathrm{and} \mathrm{T/P}$ maps, respectively, that corresponds to a rms error of $3.3 \mathrm{~cm}$ $\mathrm{rms}$ and $2.49 \mathrm{~cm}$ rms. This improvement is clearly seen in the Fig. 1c where the large scale error is removed. However, it must also be noted that the errors associated with some mesoscale structures situated far from the coast are weaker. Near the coast, it seems that the level of the error still remains significant. This is probably due the systematic rejection of coastal data that do not reach a sufficient quality in near real time.

Finally, the statistical results obtained by season (winter and summer) tend to show that the error is bigger in winter than in summer. The mesoscale activities, assumed to be more intense during winter in the Mediterranean sea, and less resolved in NRT, probably explain these results.

\subsection{SST}

The sources of error in the determination of the SST from near real time data are somehow different from those causing differences between NRT and DT altimeter data. Obviously,
Table 2. Mean bias error (MBE) and RMS of the differences between NRT and delayed time SST maps

\begin{tabular}{lll}
\hline & MBE & RMS \\
\hline $\begin{array}{l}\text { annual } \\
\text { AVHRR }\end{array}$ & -0.30 & 0.93 \\
\hline $\begin{array}{l}\text { winter } \\
\text { AVHRR }\end{array}$ & 0.38 & 0.55 \\
\hline summer & & \\
AVHRR & -0.74 & 0.74 \\
\hline
\end{tabular}

the fact that delayed time SST data are computed from algorithms that are calibrated monthly while near real time coefficients are fixed from climatological values is the main source of observed differences. Pathfinder data are computed using a function that is statistically regressed against in situ measurements of SST to obtain all the coefficients on a monthly basis, using a 5-month running window with linear weighting. As a consequence, the average difference between in situ measurements of SST and Pathfinder is very low, attaining $0.07 \pm 0.31^{\circ} \mathrm{C}$ in the case of MAERI (Marine Atmosphere Emitted Radiance Interferometer) measurements (Kearns et al., 2000).

Additional errors could be due to the different cloud detection algorithms and interpolation methods used to build Pathfinder and MFSPP maps. Moreover, Pathfinder automatically rejects data that are closer than $9 \mathrm{~km}$ to the coast, while MFSPP data use all data originally available at $1 \mathrm{~km}$ resolution. The statistical results obtained are summarized in Table 2. The mean bias between NRT and DT data was found to be $-0.30^{\circ} \mathrm{C}$, with an associated rms of $0.93^{\circ} \mathrm{C}$. However, these parameters present a clear seasonal variation, as the mean bias error was found to be $0.38^{\circ} \mathrm{C}$ for the winter season and $0.78^{\circ} \mathrm{C}$ for the summer season, while the rms was around $0.55^{\circ} \mathrm{C}$ in winter and $0.74^{\circ} \mathrm{C}$ in summer. The difference between NRT and DT data (not shown) does not present a particular spatial pattern, evidencing that the procedure applied by CMS correctly merges the western and eastern images. Only along the eastern borders of the Mediterranean sea (narrow area east of Cyprus) a higher difference is found, probably due to the necessity to use AVHRR border data more often. This is due to the geographical position of CMS and IFA stations, located in Lannion (France) and Rome (Italy), respectively. CMS and IFA cannot acquire all AVHRR passages centred on the easternmost area of the Mediterranean. On the contrary, Pathfinder uses all the GAC (Global Area Coverage) data and can therefore discard those acquired with satellite angle of view greater than $45^{\circ}$, better correcting for water vapour content in the atmosphere. 
RMS of SLA (TPERS)
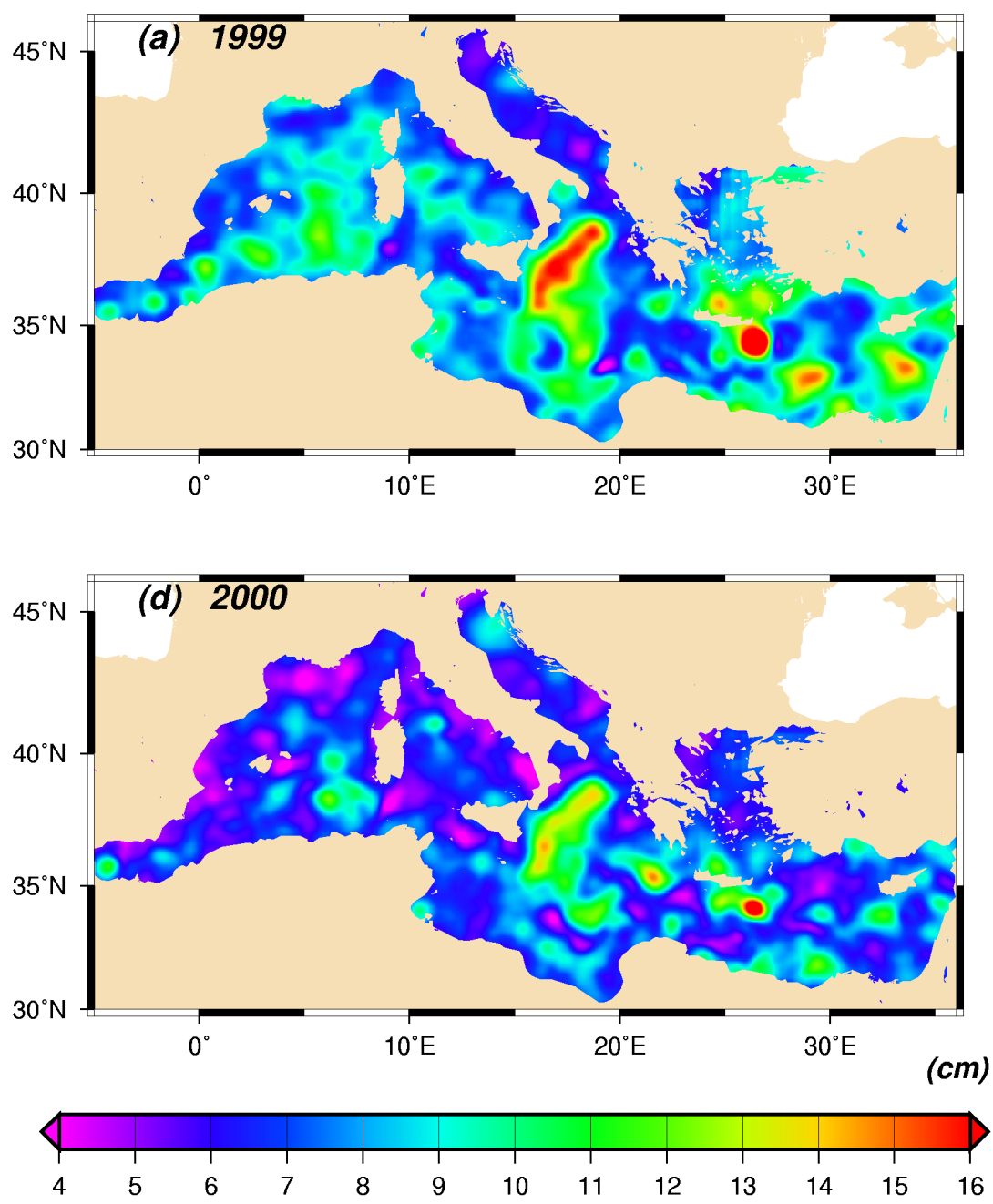

Fig. 2. RMS of SLA observed by T/P and ERS. Units are in cm. (a) for 1999 year, (b) for 2000 year.

\section{Temporal context of the operational phase}

Despite the numerous studies lead during the last two decades that have helped us to propose a scheme of the 3D circulation of the Mediterranean sea (WMCE: Western Mediterranean Circulation Experiment, La Violette, 1990, POEM: Physical Oceanography of the Eastern Mediterranean, Malanotte-Rizzoli and Robinson, 1989), the surface circulation and its variability was poorly observed before the coming of the remote sensing data. The SST and the altimetric data have, for instance, considerably improved the knowledge of the sea surface variability. This is characterised by a complex combination of transient, seasonal and interannual signals (Matteoda and Glenn, 1996; Horton et al., 1994; Roether et al., 1996; Marullo et al., 1999a, b; Santoleri et al., 1994). The importance of the latter with respect to the others implies some difficulties to propose a stable seasonal scheme for the surface circulation. However, in a recent analysis done with a long time series of altimetric maps (years 1993-1999) Larnicol et al. (2002) explored the permanent, recurrent or transient nature of the main structures of the Mediterranean. In view of their results, it seems important to identify the temporal context of the MFSPP operational phase (i.e. 1999 and 2000) from altimeter data. Additional information have been obtained from the comparison of the mean SST fields during MFSPP with climatological means obtained from Pathfinder dataset and from previous works on MCSST (Marullo et al., 1999).

A first way to characterise the surface circulation during the operational phase is to look at the rms of SLA for 1999 and 2000 (Fig. 2) and to compare their intensity and spatial structure with the ones obtained during the 1993-1999 period in the frame of the MATER project (Mass Transfer and Ecosystem Response-Mediterranean Sea MAST III Regional Sea Project). Although the error associated to the NRT maps is of about $3-4 \mathrm{~cm}$ rms, the analysis of the rms maps allows us to confirm or not the occurrence of the major structure of the Mediterranean sea circulation.

The rms of SLA ranges between 4 and $16 \mathrm{~cm}$, with a mean 


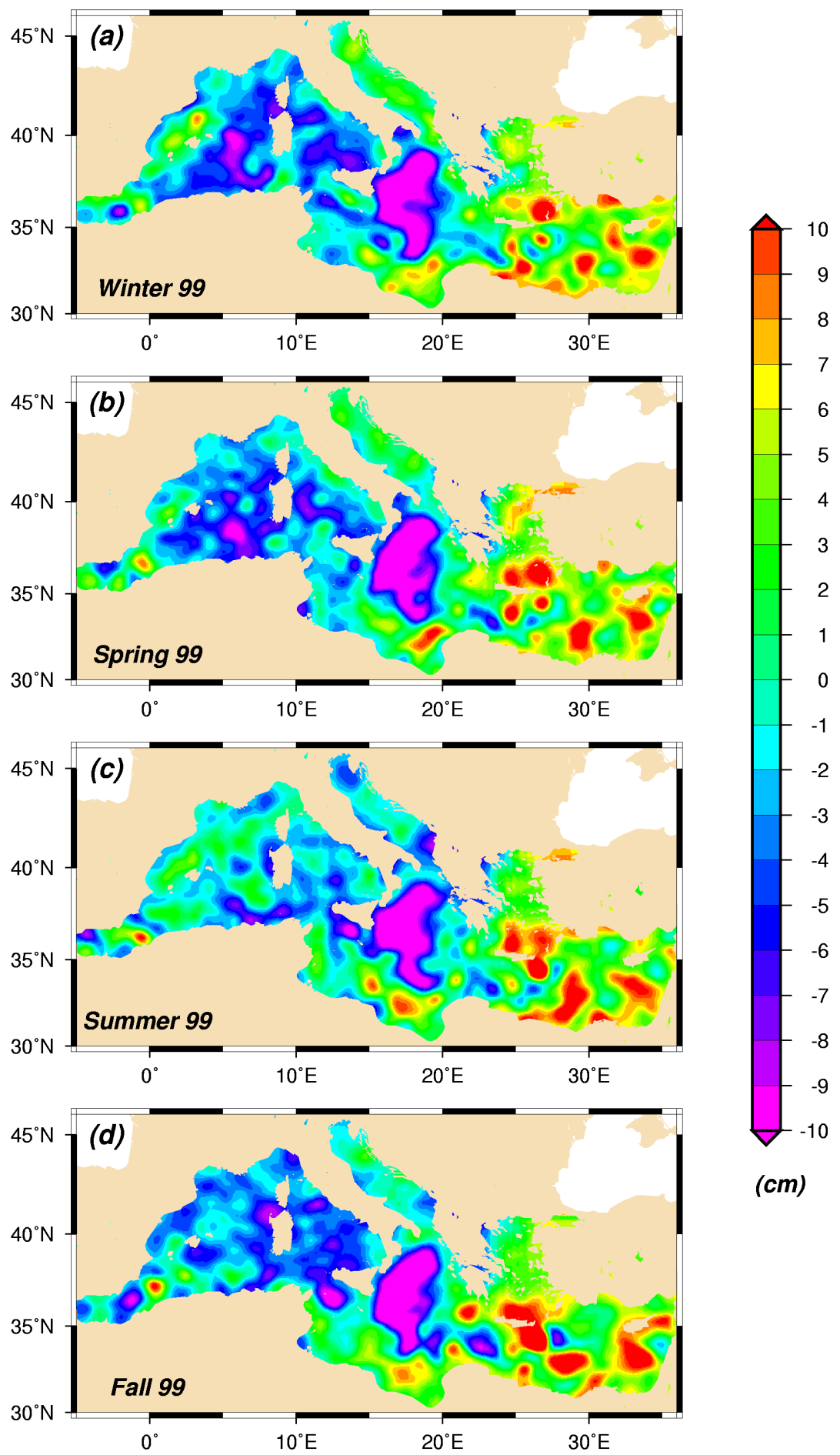

Fig. 3a. SLA seasonal means deduced from combined maps of T/P and ERS. Units are in cm. (a) Winter 1999, (b) Spring 1999, (c) Summer 1999, (d) Fall 1999.

value of about $7-8 \mathrm{~cm}$, and its spatial pattern (Fig. 2) substantially recalls the classical picture of the Mediterranean sea, with higher values concentrated in the regions characterized by intense mesoscale activity (Algerian current, Alboran gyres, Ierapetra eddy). Similarly, SST mean fields do not present significant differences respect to climatolog- ical means (not shown). However, this description of the Mediterranean sea variability is modulated by some interannual changes. Firstly, a net decrease of the background intensity was observed in 2000 respect to the first year of the MFSPP period. This could be induced by a less intense steric annual cycle, as we do not observe such a decrease for 


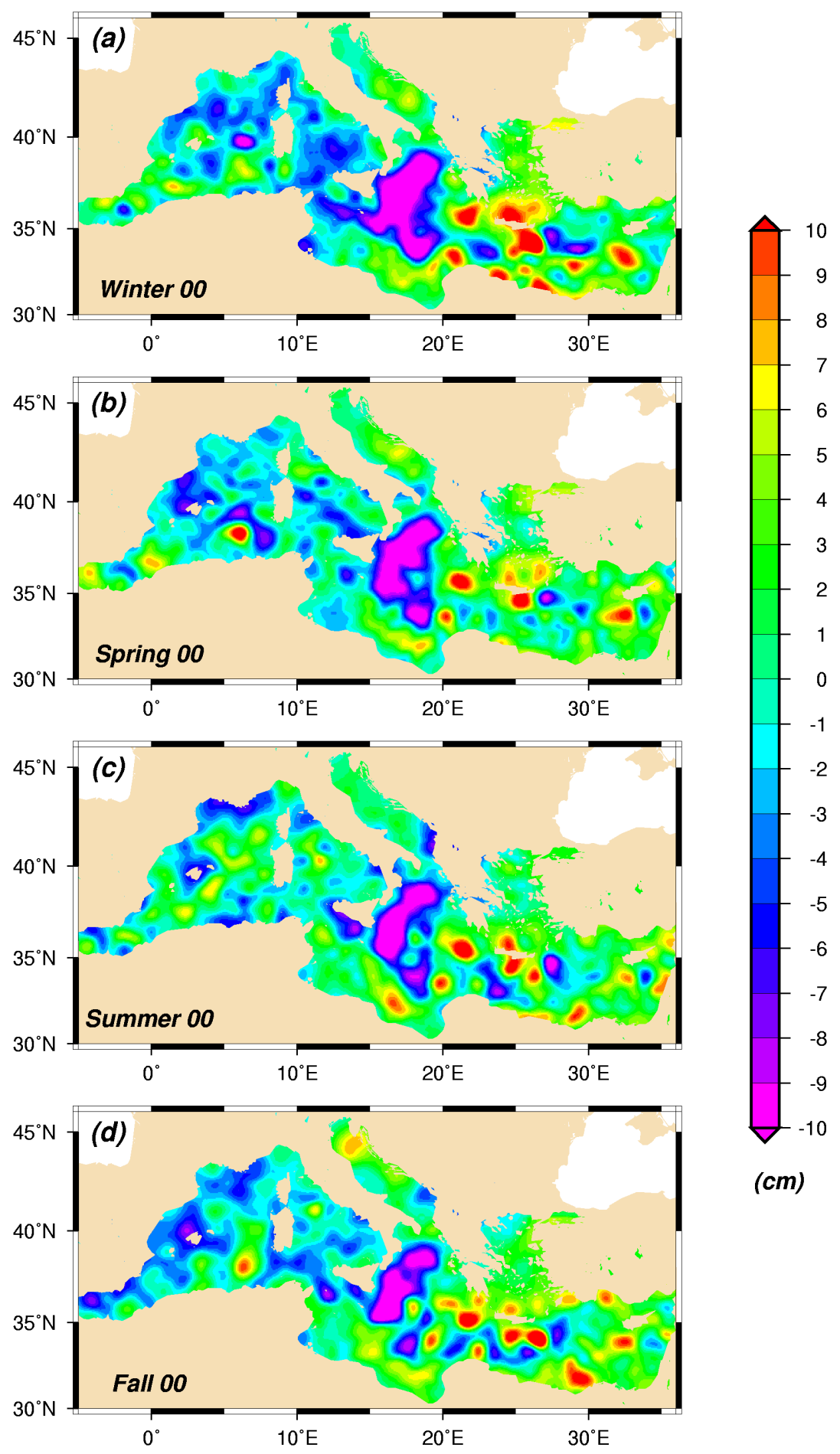

Fig. 3b. SLA seasonal means deduced from combined maps of T/P and ERS. Units are in cm. (a) Winter 2000, (b) Spring 2000, (c) Summer 2000, (d) Fall 2000.

mesoscale structures like Alboran gyres, Ierapetra or Pelops eddies.

The most intense signal in the Mediterranean sea is located around Ierapetra eddy (south-east of Crete island), which was well developed during MFSPP, as clearly confirmed by the analysis of SST data. Nevertheless, the analysis of the past years done by Larnicol et al. (2002, Fig. 3) shows that Ierapetra eddy is not really a permanent component of the Levantine circulation, but it rather presents bimodal variations with appearance and disappearance periods. In effect, the intermittent presence of Ierapetra eddy was already revealed by the analysis of ten years of SST maps by Marullo et al. 
(1999b). On one hand, a well defined and intense Ierapetra eddy is located near the southern corner of the Cretan Island. It has a clear seasonal cycle with an intensification in summer. On the other hand, a large anticyclone replaces this structure in the south. Besides that, Ierapetra eddy is found to be present from 1993 to 1995 and to disappear between 1996 and 1997. 1996 and 1998 are probably transitions years. Finally, the NRT maps of MFSPP (both SLA and SST) reveal that this eddy appears again in 1999 and is still present in 2000. So, the MFSPP operational phase is concurrent to the presence of Ierapetra eddy. As expected, the signal associated to this structure reaches its maximum in the SLA during summer, with values of about $30 \mathrm{~cm}$ in 1999 and $25 \mathrm{~cm}$ in 2000, while the strongest thermal gradient with the surrounding areas (Rhodes gyre) are found in autumn (not shown). This is probably due to the fact that the SST in that area can be considered more as a passive tracer than as an indicator of the dynamics.

A second intense signal was observed during the operational phase in SLA in the whole Ionian basin, with rms values up to $13 \mathrm{~cm}$. It has already been shown in previous papers on SST data (Marullo et al., 1999b) that the Ionian Basin is characterized by a multi-year cycle affecting the path of the AIS (Atlantic Ionian Stream) jet entering the Sicily Channel. From 1985 until 1990, a zonal pattern of the isotherms seemed to indicate that the AIS jet followed an eastward path towards the African coast. A different pattern was found in 1984, and from 1991 until 1997 (Pathfinder data, not shown), when the warm waters that usually occupy the Gulf of Syrte were spread over the Ionian interior and presented a strong thermal front due to the AIS jet bending northeastward along the Italian coastlines. In this period, thus, the AIS jet formed a marked meander that delimited an overall anticyclonic region in the Ionian interior. After 1997 a gradual return to the "classical" situation was evident in both Pathfinder and MFSPP SST data (not shown).

Similarly, Larnicol et al. (2002) showed that drastic changes occurred since 1997 with a new development of a strong cyclonic gyre in the Ionian basin. However, the analysis of the SLA seasonal means for 1999 and 2000 reveals that the large cyclonic structure seen since 1997 has a strong interannual variability, especially in the south of the basin. In fall 2000, the cyclonic gyre observed in SLA maps seems to be confined in the Northwest of the basin, like at the beginning of 1997. It is thus evident that the Ionian basin is characterized by a strong interannual variability.

The following of this section gives a synthesis of the eddies observed during the MFSPP operational phase. The aim of this paragraph is not to completely describe their variability but rather to point out their occurrence or absence. The Pelops eddy, located south of the Peloponnese peninsula, is one the most dominant structure of the Ionian basin and was very well developed in 2000 , with a value of about $20 \mathrm{~cm}$ during summer. It is less intense in $1999(15 \mathrm{~cm})$, but as in the case of Ierapetra eddy, the Pelops eddy seems to be present all along the MFSPP operational phase. Actually, looking at SST data (not shown) it is evident that this feature appears in the autumn 1999 and is strongest during winter 2000. South of this structure a clear sign of the western Cretan gyre (cyclone) is found mainly in the SST, but also in the SLA data during the MFSPP period.

As in 1996 and 1997, when large Algerian anticyclonic eddies were detected, a large eddy was observed near the Almera-Oran front during almost one year, between spring 1999 and spring 2000 (Fig. 3). Another eddy seems to appear just to the east of the Almeria-Oran front during spring 2000, and is probably present until the end of 2000 (Fig. 3). These two eddies are the largest eddies observed in the NRT SLA maps. A strong signal in the SLA and SST maps was also observed in the Balearic islands during autumn 1998 and winter 1999. This corresponds to an isolated eddy that completely changed the circulation in the Balearic sea. A complete review of the appearance, life and disappearance of this feature is given in Pascal et al. (2000). Concerning the Alboran gyres, their classical seasonal cycle is not as well resolved as in the DT maps. Nevertheless, looking at the monthly means (not shown), we are able to observe a maximum anticyclonic development of both gyres.

\section{The Singular Value Decomposition of the Cross- covariance of the data (SVDC)}

The coupled pattern analysis (CPA) is a technique to isolate coupled modes of variability between time series of two fields, in this case SST and SLA. The approach that has been adopted here is a singular value decomposition of the covariance of the two geophysical fields (Bretherton et al., 1992; Leuliette and Wahr, 1998).

SVD is a generalization of the diagonalization procedure that is performed in principal component analysis (PCA) to matrices that are not square or symmetric. SVD of the crosscovariance matrix (SVDC) identifies pairs of spatial patterns that generally explain the mean-squared temporal covariance between the two fields. The cross-covariance matrix between the field $\mathbf{s}(t)$ and $\mathbf{z}(t)$ is defined as:

$\boldsymbol{C}_{s z}=<s(t) z^{T}(t)>\left(N_{s} \times N_{z}\right)$.

In general, the data time series $\mathbf{s}(t)$ and $\mathbf{z}(t)$ at each of the grid point can be expanded in terms of a set of $\mathrm{N}$ vectors, $\boldsymbol{p}_{k}$ and $\boldsymbol{q}_{k}$, called patterns:

$\boldsymbol{s}(t)=\sum_{k=1}^{N} a_{k}(t) \boldsymbol{p}_{k} \quad \boldsymbol{z}(t)=\sum_{k=1}^{N} b_{k}(t) \boldsymbol{q}_{k}$

The time series $a_{k}(t)$ and $b_{k}(t)$ are called expansion coefficient, those are calculated as weighted linear combination of the gridpoint data:

$a k(t)=\boldsymbol{p}_{k}^{T} \boldsymbol{s}(t) \quad b_{k}(t)=\boldsymbol{q}_{k}^{T} \boldsymbol{z}(t)$

In SVDC, the first patterns $\boldsymbol{p}_{1}$ and $\boldsymbol{q}_{1}$ are chosen as follows: the projection $a_{1}(t)$ of $\mathbf{s}(t)$ on $\boldsymbol{p}_{1}$ has the maximum covariance with the projection $b_{1}(t)$ of $\mathbf{z}(t)$ on $\boldsymbol{q}_{1}$. Successive pairs 
$\left(\boldsymbol{p}_{k}, \boldsymbol{q}_{k}\right)$ are chosen exactly in the same way, with the additional condition that $\boldsymbol{p}_{k}$ is orthogonal to $p_{1} \cdots p_{k-1}$ and $\boldsymbol{q}_{k}$ is orthogonal to $q_{1} \cdots q_{k-1}$. The patterns $\boldsymbol{p}_{k}$ and $\boldsymbol{q}_{k}$ result to be the right and left singular vectors of the cross-covariance matrix $\boldsymbol{C}_{s z}$.

Applying SVD, any $N_{S} \times N_{z}$ matrix $\boldsymbol{C}$ can be decomposed uniquely as follows:

$\boldsymbol{C}=\sum_{k=1}^{R} \sigma_{k} \boldsymbol{l}_{k} \boldsymbol{r}_{k}^{T}, \quad R \leq \min \left(N_{s}, N_{z}\right)$

where the $\boldsymbol{l}_{k}$ are an orthonormal set of $\boldsymbol{R}$ vectors of length $N_{s}$ called the left singular vectors, the $\boldsymbol{r}_{k}$ are an orthonormal set of $\boldsymbol{R}$ vectors of length $N_{z}$ called the right singular vectors, and the $\sigma_{k}$ are nonnegative numbers called the singular values, ordered such that $\sigma_{1} \geq \sigma_{k} \geq \cdots \geq \sigma_{k}$ and $R$ is the rank of $\boldsymbol{C}$. From (1), since both $\boldsymbol{l}_{k}$ and $\boldsymbol{r}_{k}$ are orthonormal set, then

$$
\boldsymbol{C}^{T} \boldsymbol{l}_{k}=\sigma_{k} \boldsymbol{r}_{k}, \quad \boldsymbol{C} \boldsymbol{r}_{k}=\sigma_{k} \boldsymbol{l}_{k},
$$

The $\sigma_{k}^{2}$ are the $R$ nonzero eigenvalues of $\boldsymbol{C}^{T} \boldsymbol{C}$ and $\boldsymbol{C} \boldsymbol{C}^{T}$, the remaining eigenvalues are zero, $\boldsymbol{l}_{k}$ and $\boldsymbol{r}_{k}$ are the eigenvectors, with non negative eigenvalues, of $\boldsymbol{C} \boldsymbol{C}^{T}$ and $\boldsymbol{C}^{T} \boldsymbol{C}$, respectively.

If $\boldsymbol{C}$ is our cross-covariance matrix, it can be demonstrated that the maximum covariance is equal to the largest singular value $\sigma_{1}$ and is obtained by projecting the left field $\mathbf{s}(t)$ onto the first left singular vectors and the right field $\mathbf{z}(t)$ onto the first right singular vectors. Similarly, the subsequent pairs of patterns can be obtained with the constraint of orthogonality to the previous patterns. The SVDC is only an algebraic decomposition of the initial data-sets. Consequently, some additional parameters must be computed in order to characterize the significance of each pair of patterns (mode). First of all, the squared covariance factor (SCF), defined as:

$$
S C F=\frac{\sigma_{k}^{2}}{\sqrt{\sum_{l=1}^{n-1} \sigma_{k}^{2}}}
$$

which is a measure of the fraction of the total covariance explained by the $k$ th pair mode. A measure of the similarity of the two patterns is then given by the spatial correlation defined as:

$$
r_{k}^{\text {space }}=\frac{\sum_{x} \boldsymbol{l}_{k}(x) \boldsymbol{r}_{k}(x)}{\sqrt{\sum \boldsymbol{l}_{k}^{2}(x) \sum \boldsymbol{r}_{k}^{2}(x)}}
$$

In a similar way, the temporal correlation coefficient measures the correlation between the temporal coefficients as:

$r_{k}^{\mathrm{time}}=\frac{\sum_{t} a_{k}(t) b_{k}(t)}{\sqrt{\sum a_{k}^{2}(t) \sum b_{k}^{2}(t)}}$

Other useful instruments that can be computed to help the physical interpretation of the SVDC modes are homogeneous and heterogeneous correlation maps. The homogeneous correlation maps are indicators of the geographic localisation of the covarying part of the fields, while the heterogeneous correlation maps indicate how well the gridpoints in one field can be predicted from the expansion coefficient derived from the other field. The $k$ th left homogeneous correlation map $r\left[s(t), a_{k}(t)\right]$ is easily computed as the correlation between the gridpoint values of the left field and the $k$ th left expansion coefficient. Similarly, the $k$ th left heterogeneous correlation map $r\left[s(t), b_{k}(t)\right]$ is the correlation between the gridpoint values of the left field and the $k$ th right expansion coefficient. Analogous correlation maps can obviously be constructed for the right field.

\section{Analysis of the coupled patterns}

The method described in Sect. 5 is applied here to the first two years of MFSPP SSTA and SLA data. In Fig. 4 the first coupled mode is presented. This mode is mainly associated with the seasonal steric effect, as clearly evident from the temporal expansion coefficients, which closely follow the basin average response both in the SSTA and in the SLA (Fig. 11). The seasonal cycle substantially dominates the variability of the two fields, explaining all of the observed covariance (99\%). However, if we limit our analysis at this step, no information on the variability on other scales can be extracted. In addition, the SST and SLA fields exhibit a temporal correlation of 0.57 , which is not low, but not as high as one would expect for a strong coupling of the phenomena considered. The seasonal variation of the SST temporal coefficient (or average basin response Fig. 11) appears to lead that of SLA. This fact can be associated to the Mediterranean sea complex thermal and mass balance, and to the fact that SST response to heat fluxes is related to the thermocline depth variation. If the SST is decreasing (as for example between week 45 and week 60), the thermal component of the buoyancy flux at the surface is negative and consequently the SLA should drop off, which is not the case. There are evidently only few possible explanations for the observed behaviour of SST and SLA temporal coefficient. If we suppose the Mediterranean to be mass balanced at the seasonal scale, then the density (and consequently the volume or SLA) could only be modified by a deep "source" of heat and salt (exchange at Gibraltar) or by a negative flux of salt at the surface, given, for example, by the river runoff and precipitation (for the role of salinity on SLA variations, see Sato et al., 2000; Maes, 1998). Moreover, some hypothesis have been made about the possibility that the Mediterranean is not in mass balance at seasonal timescales, so that a net influx of mass (and also of heat and salt) could produce the observed mean sea level variations (Ovchinnikov, 1974; Larnicol et al., 1995), even if field experiments have not confirmed this hypothesis until now (Bryden and Pilsbury, 1990).

Going back to the first mode, a low spatial correlation (.20) is also found, stressing the complexity of the processes included in this mode. Consequently, from the coupled pattern 

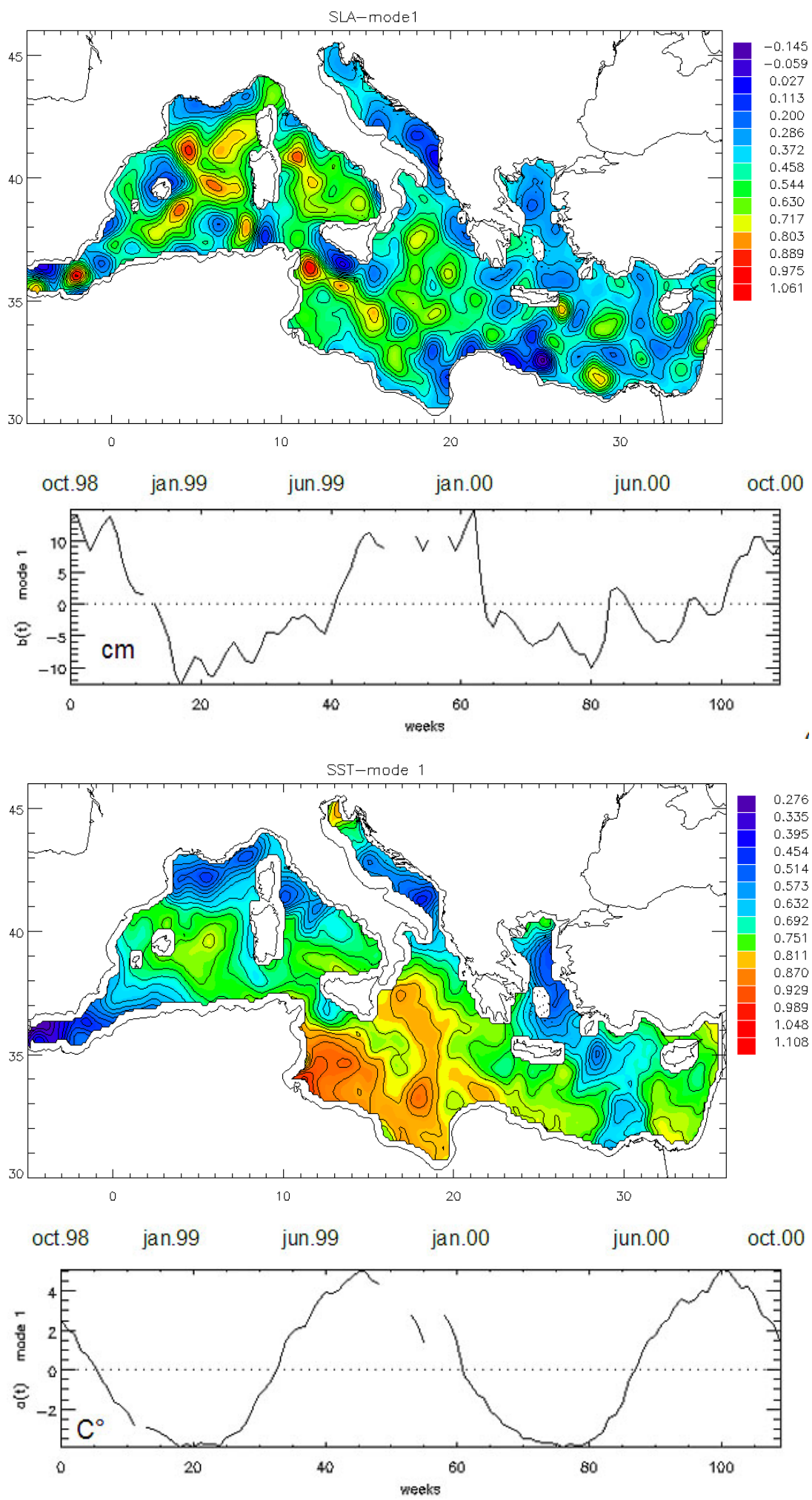

Fig. 4. First mode derived from the coupled pattern analysis of SLA and SSTA data collected during the two years of MFSPP. Patterns and associated temporal coefficients: (a) SLA pattern, (b) SLA temporal coefficient, (c) SST pattern, (d) SST temporal coefficient.

analysis of the SSTA and SLA alone, it is not possible to recognize and discriminate the response at the larger temporal and spatial scales from those associated with processes on smaller scales (sub-basin/mesoscale features). Moreover some problems could arise when mesoscale features have a clear seasonal cycle, as for the Alboran gyres (see Fig. 4), or 

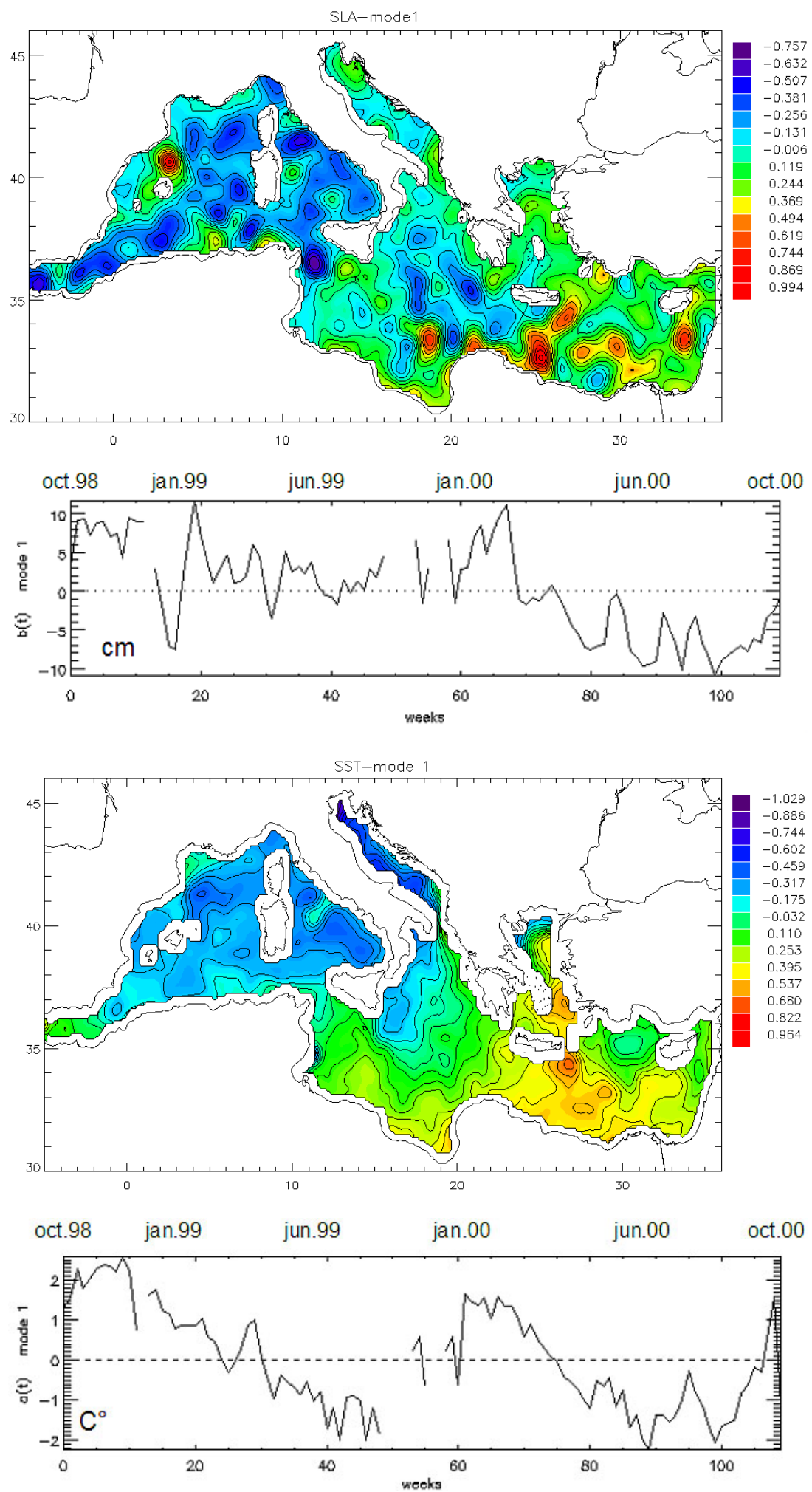

Fig. 5. First coupled mode of SLA and SSTA data collected during MFSPP after removing the spatial averages over the basin ("gradient CPA"). Patterns and associated temporal coefficients: (a) SLA pattern, (b) SLA temporal coefficient, (c) SST pattern, (d) SST temporal coefficient.

where the SST gradient is not very strong (for structures at mesoscale, SST sometimes behaves as a passive tracer). A typical procedure adopted at this point is to perform a new analysis after the removal of the seasonal signal, in order to 

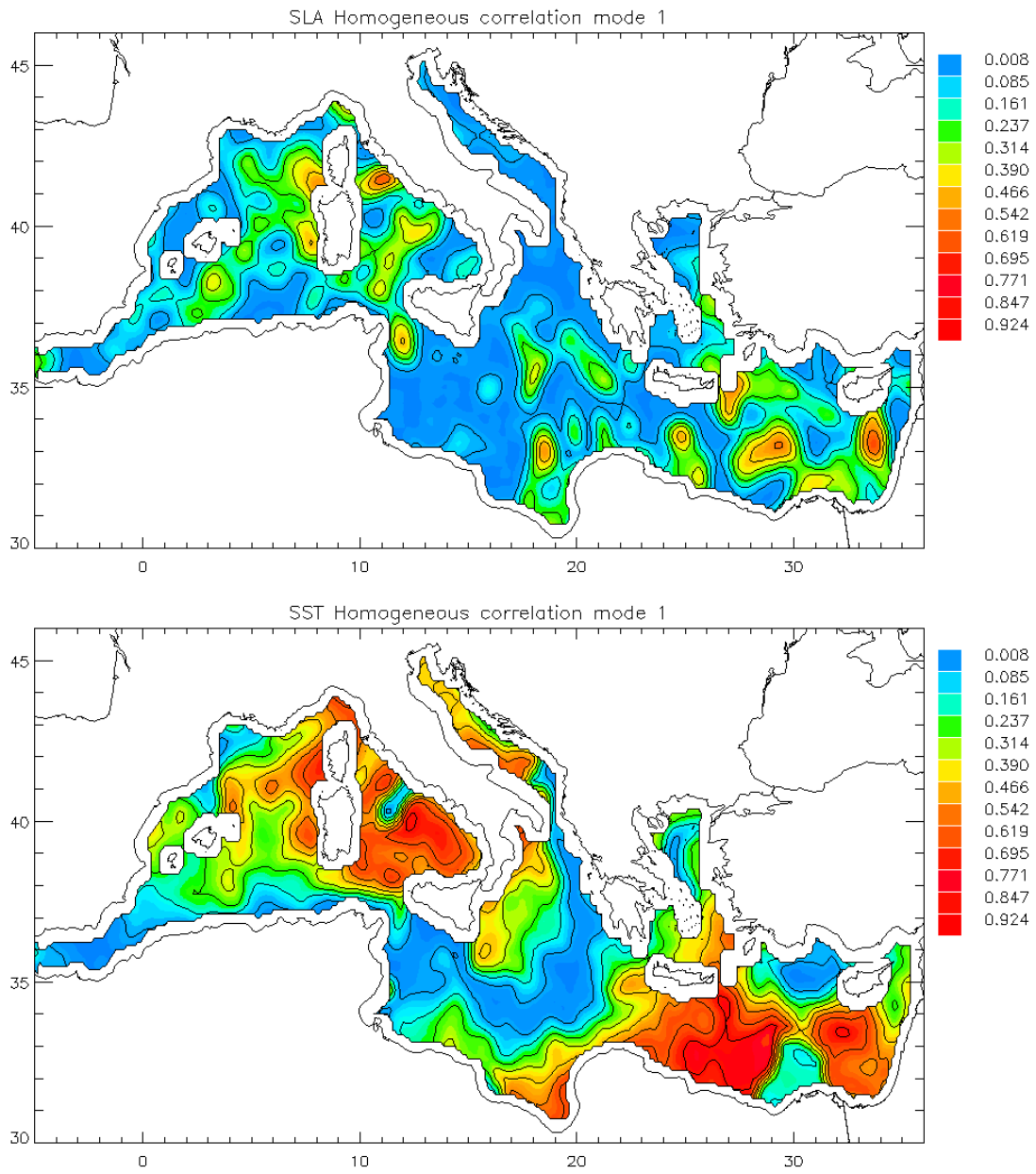

Fig. 6. SLA (a) and SSTA (b) homogeneous correlation maps relative to the first "gradient CPA" mode.

accentuate the variability on the other scales. The typical steps in that method are the local (or at least latitudinal) fit of the seasonal signals to a sinusoid and its subsequent removal from the original data-sets. In spite of this, the seasonal response of primarily the surface height, but also of the SST, can hardly be considered sinusoidal, being related to the effective heat content of the water column, which is given by the integral in time of the local surface heat fluxes and of the advective terms. Moreover, we do not expect the relation between SST and SLA to be linear, as far as strong spatial and temporal variations of the mixed layer depth have to be taken into account. In addition, the fluxes on the Mediterranean can hardly be considered purely zonal, as strong contributions result from the local winds constrained by the orography surrounding the basin. Removing a local sinusoidal fit could consequently result in a net addition of a spurious signal, that does not contain any physical significance. However, this method has been tested on MFSPP data, and effectively resulted in very low correlated patterns and temporal coefficients (not shown), which means that the method failed in searching physically coupled modes.

In the following, we therefore preferred limiting analysis to the subtraction of the basin-wide weekly average from each map. This procedure is the same as that applied in the calculation of 'gradient EOFs' (see as an example, Marullo et al., 1999a) and substantially removes the basin average response to any time-varying signal, both interannual, seasonal and on other scales ("gradient CPA"). For instance, high frequency scales induced by inverse barometer effect, that cause differences of the order of few $\mathrm{cm}$ (up to $\sim 10 \mathrm{~cm}$ ) between 2 consecutive cycles in the Mediterranean sea, are removed by this procedure, which preserves the spatially variable component, basically allowing a better spatial identification of the characteristic modes of covariance.

After removing the spatial averages, new coupled modes are obtained. The first mode, presented in Fig. 5, explains $74 \%$ of the covariance, and is also characterized by a strong temporal and spatial correlation (0.78 and 0.55 , respectively), indicating that the patterns are not simply the result of a mathematical decomposition but should be related to a specific physical mechanism. This consideration is supported by the comparison of SLA and SST homogeneous correlation maps (Fig. 6), that display the maximum correlation in the same areas (central western basin and southern Levantine). Despite the patchiness observed in the SLA pattern, clearly due to the sampling and interpolation of altimeters' data, this 

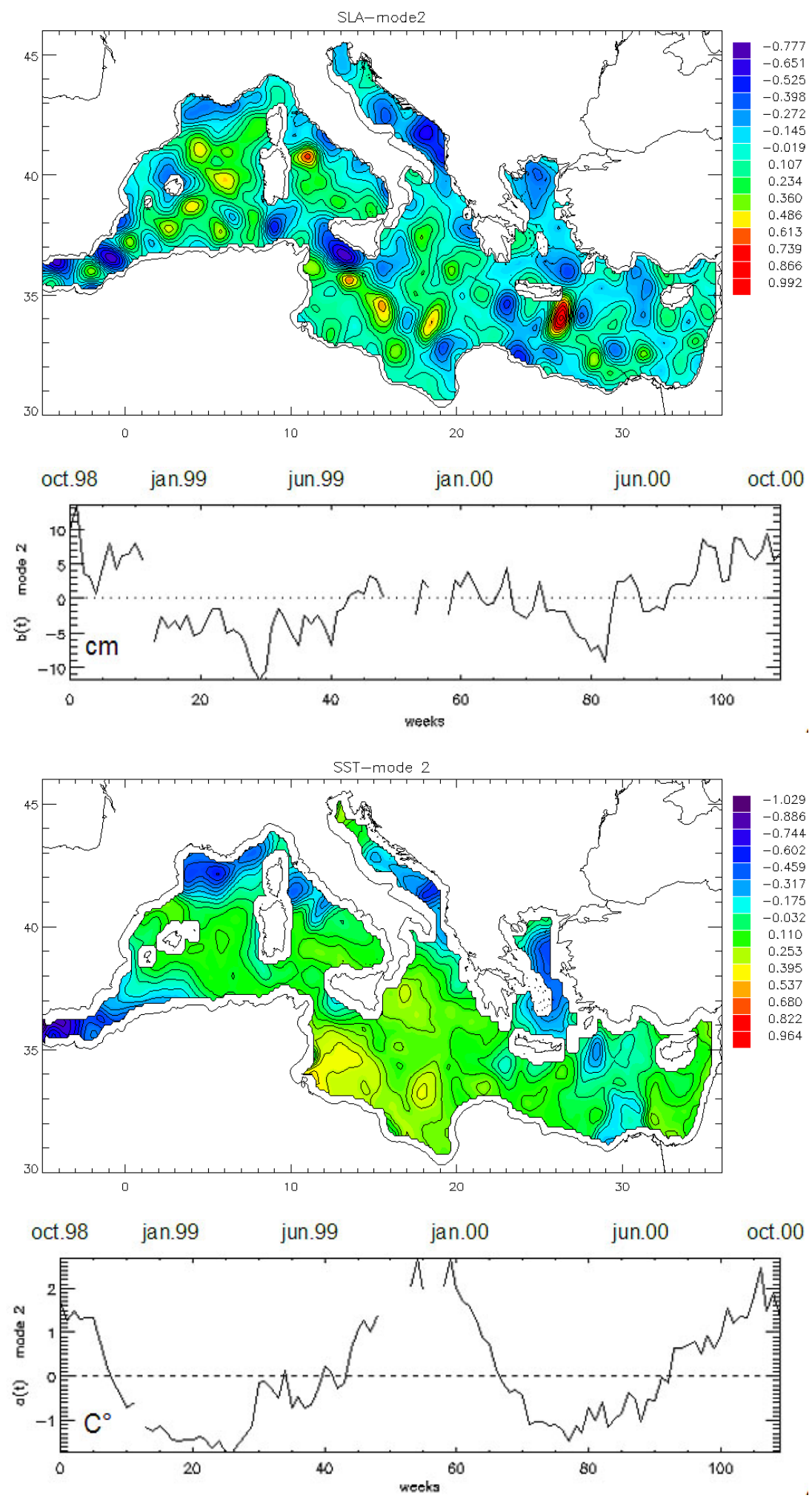

Fig. 7. Second "gradient CPA" mode of SLA and SSTA data collected during. Patterns and associated temporal coefficients: (a) SLA pattern, (b) SLA temporal coefficient, (c) SST pattern, (d) SST temporal coefficient.

first mode is mainly characterized by a large scale pattern, even though some smaller scale features can be recognized (such as the small anticyclone in the northern Balearic sea or the Ierapetra gyre, south of Crete). The large scale field can be more or less described as a western basin/eastern basin gradient, sloping from the north-west to the south-east, with 

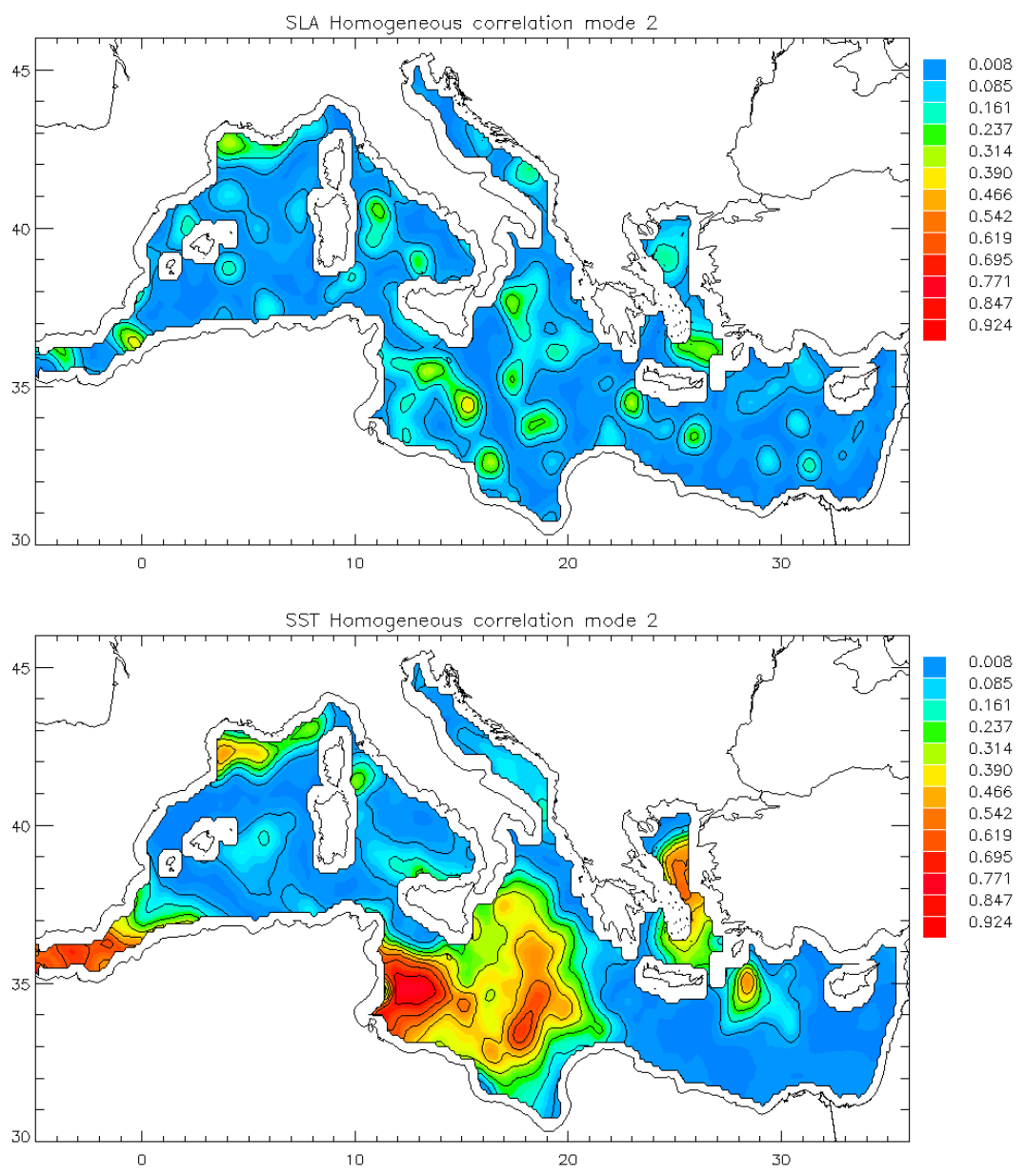

Fig. 8. SLA (a) and SSTA (b) homogeneous correlation maps relative to the second "gradient CPA" mode.

a minimum occupying almost all the western Mediterranean and a maximum in the Levantine basin. What is noteworthy is that the temporal coefficients associated to this first mode seem to contain an interannual tendency (better detectable in the SLA coefficient) to gradually reduce and eventually invert the gradient, even if two years are a short period to detect clear interannual trends. In addition, we can observe that this mode possibly explains the difference in the mean sea level variability as observed in Sect. 4.

The temporal coefficients also reveal a seasonal signal that accounts for an inversion of the gradient between the western and eastern basins from winter to summer. This is more evident in the SST coefficient, that presents a gradual decrease from December 1998 to mid-August 1999, then a rapid increase until January 2000 and again a slow decrease to midAugust 2001. Actually, it seems that the rapid increase of the temporal coefficient of the SST occurs exactly in the periods when the average SST is decreasing and the average SLA is slightly increasing (Fig. 11). As a matter of fact, however, if no other data are used, only hypothesis can be done on the physical interpretation of that mode. In fact, the observed variation could be explained by different heat fluxes (interannual trend) or/and by different wind-induced mixing (seasonal signal) over the two sub-basins, even if the possible role or consequences on the exchanges at the straits (Gibraltar and Sicily) should be considered.

The second mode (Fig. 7) is responsible for a relatively high percentage of the total covariance (20\%) and displays a quite interesting pattern. Again both the temporal and the spatial correlations give reasonably high values, reaching 0.77 and 0.40 , respectively. Thus, mode 2 should effectively describe a coupled pattern associated to some physical process. Both temporal coefficients present a maximum during the period from mid-August to January and a broader minimum in between, thus showing a clear seasonal cycle. The SLA coefficient appears noisier, with a maximum amplitude of generally less than $10 \mathrm{~cm}$. On the other hand, the SSTA coefficient presents a more regular behaviour, with stronger maxima (up to $\sim 3^{\circ} \mathrm{C}$ ), a more rapid decrease to a minimum greater than $-2^{\circ}$ and a very gradual increase. It should be noted that the spatial structure of this second mode is similar to that of the first mode in the first attempt. However, looking at the homogeneous correlation maps (Fig. 8), it can be observed that the second mode is fundamentally representative of very localized processes, all related to particular sub-basin scale features, except for the large scale circulation within the 

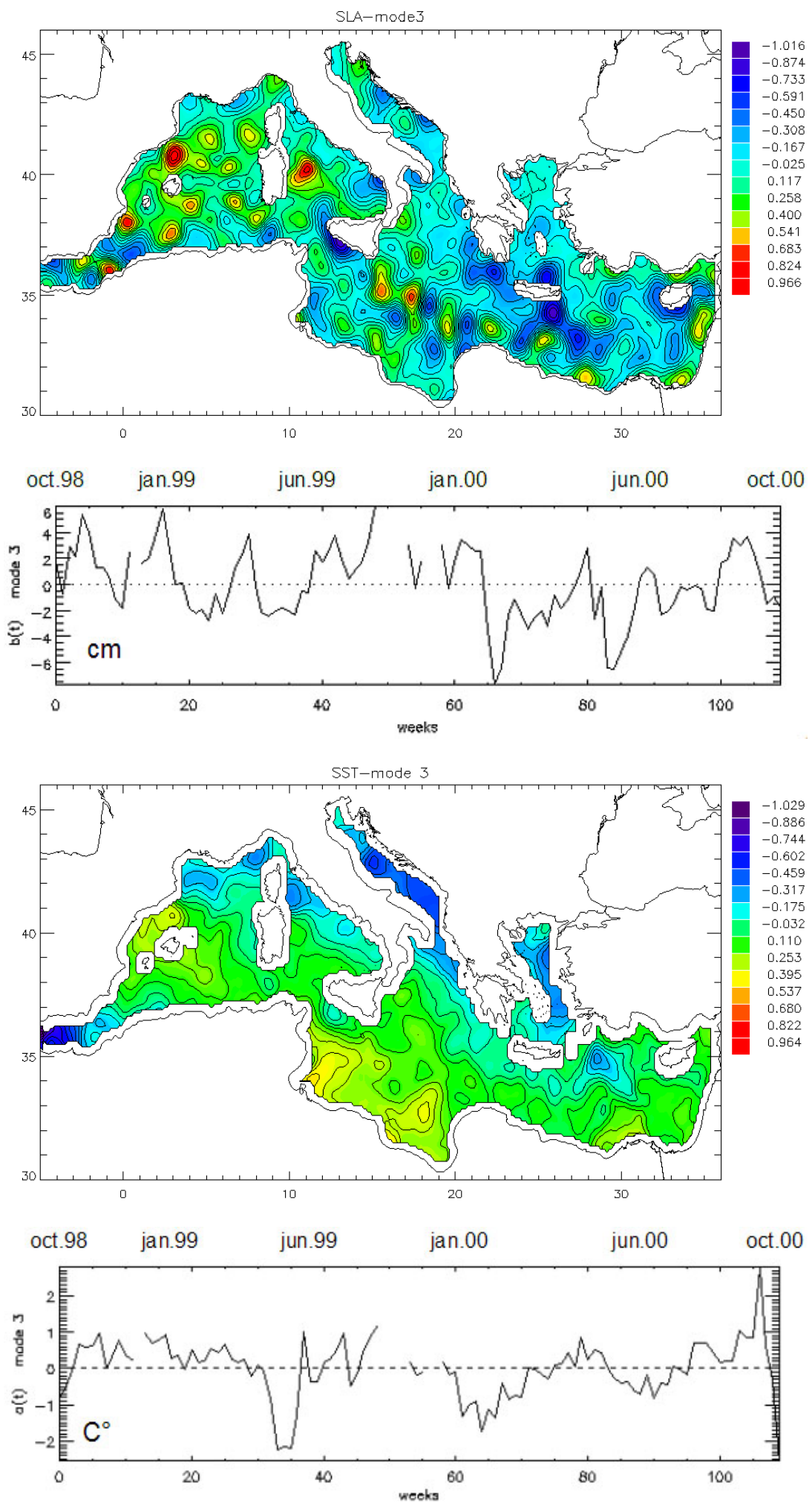

Fig. 9. Third "gradient CPA" mode of SLA and SSTA data collected during MFSPP. Patterns and associated temporal coefficients: (a) SLA pattern, (b) SLA temporal coefficient, (c) SST pattern, (d) SST temporal coefficient.

Ionian Sea. From the SST pattern, it seems that all the areas where the stratification is typically lower (dense water formation areas, upwelling areas) are identified by this mode. The large cyclonic area off the southern coast of France is clearly evident in SST and SLA patterns. The area includes: the gulf of Lions and the Ligurian Sea, the northern Tyrrenian eddy, 

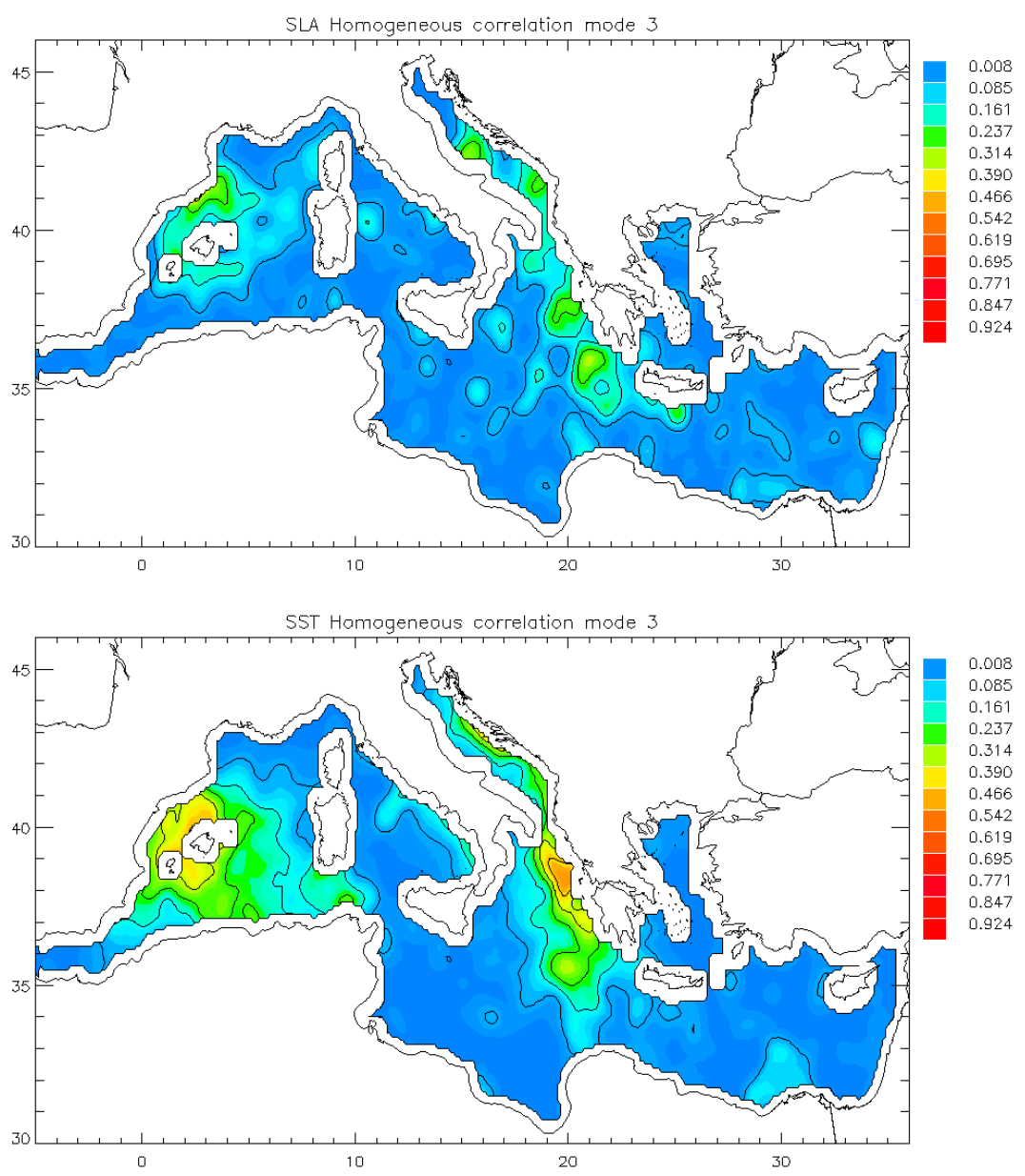

Fig. 10. SLA (a) and SSTA (b) homogeneous correlation maps relative to the third "gradient CPA" mode.

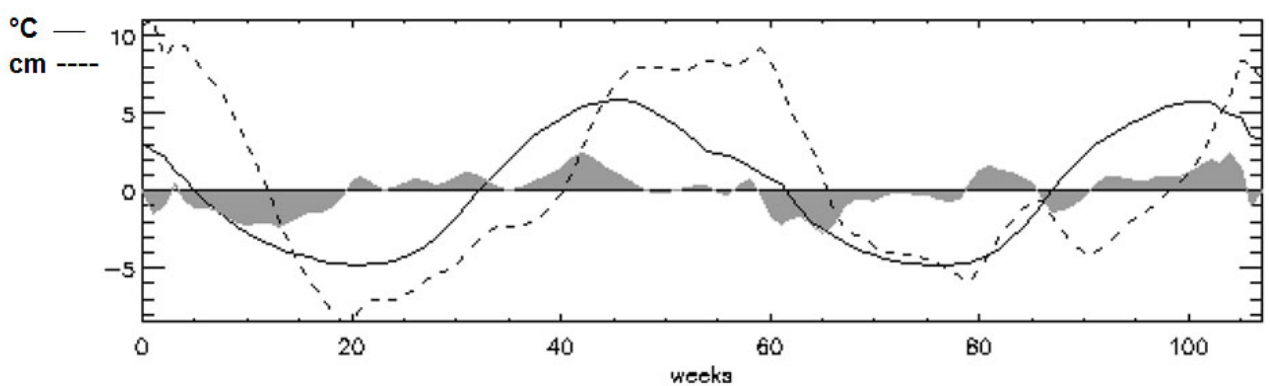

Fig. 11. SST (continuous line) and SLA (dashed line) signal averaged over the basin for the period October 1998-October 2000. The grey-shaded contour represents the time derivative of the SLA, which is proportional to the heating rate of the water column.

the central and southern Adriatic gyres, the Rhodes gyre, the upwelling filaments south of Sardinia and Sicily, and the upwelling areas along the Turkish peninsula. This is consistent with the idea that one might expect greater correlation between SST and SLA when deep mixing is present, so that SST is more representative of the deep layers, while, in presence of a shallow mixed layer, SST can be decoupled from the underlying density field.

Only a small percentage of the covariance is explained by the third mode $(6 \%)$. Moreover, the spatial correlation results are quite low (0.22) and the temporal correlation is not higher than 0.48 . Consequently, we do not consider this mode particularly significant from a physical point of view. We must conclude that both time and space scales in this mode are smaller and that the peak values of the temporal coefficients are almost half with respect to those of the other modes (Fig. 9). The homogeneous correlation maps present higher values in the Balearic Sea and along the YugoslavianAlbanian-Greek coast (Fig. 10). Modes that explain less than $6 \%$ of the variance have not been taken into account in the 
present work, as they are probably dominated by noise.

\section{Conclusions}

A system for the acquisition and processing in Near Real Time of satellite data (AVHRR, TOPEX/Poseidon, Ers-2) was developed in the framework of the MFSPP, and became operational since October 1998. The NRT data were assimilated in MFSPP general circulation model, and consequently it was initially of great interest to assess the accuracy of the NRT with respect to delayed time data, and secondly to characterize the MFSPP years with respect to the typical conditions observed in the Mediterranean sea during previous periods. Actually, NRT data were affected by errors of different nature. In facts, both SLA and SST algorithms for NRT processing are obviously less accurate than delayed time ones. SST operational algorithms process data using constant calibration coefficients, while delayed time products like Pathfinder datasets are obtained from monthly calibrated coefficients. On the other hand, orbit error contributes significantly to SLA error when estimated in NRT. Moreover, the lower spatial and temporal coverage in the NRT data is also an important source of error (more data are rejected because of the lower quality) and the space-time interpolation scheme (with a shorter time window respect to delayed algorithms) also produces additional errors in the weekly SLA maps. These errors are quantified by an rms of 3-4 cm for SLA data and by an SST mean bias error ranging between $0.38^{\circ}$ in winter and $-0.74^{\circ}$ in summer, characterized by an rms of $0.6-0.9^{\circ}$. Despite the differences observed between NRT and DT data, the MFSPP dataset adequately described the fundamental aspects of the Mediterranean circulation and allowed us to characterize the MFSPP years in a wider temporal context. Both surface height and temperature data coherently describe a surface circulation that is gradually returning to what was known in literature as the "classical" picture for the Mediterranean. This after some years being characterized by a modified circulation involving the central part of the basin, with an intense anticyclonic circulation in the Ionian sea (1991-1997). Moreover, MFSPP years are clearly characterized by the presence of Ierapetra eddy.

Finally, a methodology proposed by Leuliette and Wahr (1999) to investigate the coupling of SSH and SST has been tested on MFSPP data. This multi-variate method consists in the SVD of the covariance between SST and SSH. When this method was applied to 2 years of SSTA and SLA data without any additional processing of the maps, the first mode explained almost all the co-variability of the two fields (99\% of the covariance), with a low spatial correlation $(0.20)$ and a temporal correlation of 0.57 . Although the temporal coefficients displayed a very clear seasonal signal for both data sets, it was not possible to provide a coherent interpretation with these low-correlated spatial patterns. However, once a more refined handling of the SST and SLA maps has been decided, removing the spatial average from each map ("gradient CPA'), the co-variability of the temperature and sea sur- face heights fields was distributed in more modes (74\% of the covariance for the first mode, $20 \%$ for the second, $6 \%$ for the third ...) containing both interannual (first mode) and seasonal (second mode) signals and characterized by clear and highly correlated temporal and spatial patterns.

A longer accumulation period would allow a better identification of varying signals. In this sense, the two years of MFSPP satellite data are not the best dataset to perform an advanced analysis of the coupled patterns. However, applying this method to a limited area as the Mediterranean sea represented: (1) a test of the capabilities of this methodology on scales smaller than global scale, and (2) a first attempt at the coupled analysis of longer time series of several datasets. Further analysis will be performed as soon as coherent datasets become available (e.g. MFSPP follow on), and that should lead to a deeper understanding of ocean surface dynamics.

Acknowledgements. The DSP image processing software was developed by O. Brown, R. Evans, J. Brown, and A. Li at the University of Miami with Office of Naval Research funding. The continuing support of the Miami group is gratefully acknowledged.

Topical Editor N. Pinardi thanks T. Guymer and another referee for their help in evaluating this paper.

\section{References}

Bretherton, F., Davis, R., and Fandry, C.: A technique for objective analysis and design of oceanographic experiments applied to MODE-73, Deep Sea Res., 23, 559-582, 1976.

Bretherton, C. S., Smith, C., and Wallace, J. M.: An intercomparison of methods for finding coupled patters in climate data, J. of Climate, 5, 541-560, 1992.

Brisson, A., Le Borgne, P., and Marsouin, A.: Development of algorithms for SST retrieval at O\&SI SAF Low and Mid Latitudes. CMS report to EUMETSAT, Meteo-France/CMS 22302, Lannion, France, 1998.

Bryden, H. L. and Pillsbury, R. D.: Measurements of the flow through the straits of Gibraltar, Adv. Water Resour., 13, 64-69, 1990.

Buongiorno Nardelli, B., Santoleri, R., Marullo, S., Iudicone, D., and Zoffoli, S.: Altimetric signal and three dimensional structure of the sea in the channel of Sicily, J. Geophys. Res., 104, C9, 20 585-20 603, 1999.

Chambers, D. P., Tapley, B. D., and Stewart, R. H.: Longperiod ocean heat storage rates and basin-scale heat fluxes from TOPEX, J. Geophys. Res., 102, C12, 163-177, 1997.

D'Ortenzio, F., Marullo, S., and Santoleri, R.: Validation of AVHRR Pathfinder SST's over the Mediterranean Sea, Geophys. Res. Lett., 27, 2, 241-244, 2000.

Fukomori, I. and Wunsch, C.: Efficient representation of the north atlantic hydrographic and chemical distributions, Progress in Oceanography, Vol 27, Pergamon, 111-195, 1991.

Horton, C., Kerling, J., Athey, G., Schmitz, J., and Clifford, M.: Airborne expendable bathythermograph surveys of the eastern Mediterranean, J. Geophys. Res., 99, C5, 9891-9905, 1994.

Iudicone, D., Marullo, S., Santoleri, R., and Gerosa, P.: Sea level variability and surface eddy statistics in the Mediterranean sea from TOPEX/POSEIDON data, J. Geophys. Res., 103, 29953012, 1998. 
Kearns, E. J., Hanafin, J. A., Evans, R., Minnett, P. J., and Brown, O. B.: An independent assessment of Pathfinder AVHRR sea surface temperature accuracy using the Marine-Atmosphere Emitted Radiance Interferometer, Bulletin of the American Meteorological Society. 81, No. 7, 1525-1536, 2000.

Larnicol, G., Le Traon, P. Y., Ayoub, N., and De Mey, P.: Mean sea level and surface circulation variability of the Mediterranean Sea from 2 years of TOPEX/POSEIDON altimetry, J. Geophys. Res., 100, C12, 163-177, 1995.

Larnicol, G., Ayoub, N., and Le Traon, P. Y.: Majors changes in the Mediterranean Sea level variability from seven years of TOPEX/POSEIDON and Ers-1/2 data, to appear in June 2002 in Jour Mar. Sys, 2002.

La Violette, P.: The western Mediterranean Circulation Experiment (WMCE): Introduction, J. Geophys. Res., 95, C2, 1511-1514, 1990.

Le Traon, P. Y. and Ogor, F.: ERS-1/2 orbit improvement using TOPEX/POSEIDON: the $2 \mathrm{~cm}$ challenge, J. Geophys. Res., 103, 8045-8057, 1998.

Le Traon, P. Y. and Gauzelin, P.: Response of the Mediterranean mean sea level to atmospheric pressure forcing, J. Geophys. Res., 973-983, 1997.

Leuliette, E. W. and Wahr, J. M.: Coupled pattern analysis of sea surface temperature and TOPEX/POSEIDON sea surface height, J. Phys. Ocean., 29, 599-611, 1999.

Maes, C.: Estimating the influence of salinity on sea level anomaly in the ocean, Geophys. Res. Lett., 25, 19, 3551-3554, 1998.

Malanotte-Rizzoli, P. and Robinson, R.: POEM, Physical Oceanography of the Eastern Mediterranean, Eos Trans, AGU, 69, 4, 1989.
Matteoda, A. M. and Glenn, S. M.: Observations of recurrent mesoscale eddies in the eastern Mediterranean, J. Geophys. Res., 101, C9, 20 687-20 709, 1996.

Marullo, S., Santoleri, R., Malanotte Rizzoli, P., and Bergamasco, A.: The sea surface temperature field in the eastern Mediterranean from AVHRR data. Part I. Seasonal variability, J. Mar. Syst., 20(1-4), 63-81, 1999a.

Marullo, S., Santoleri, R., Malanotte Rizzoli, P., and Bergamasco, A.: The sea surface temperature field in the eastern Mediterranean from AVHRR data. Part II. Interannual variability, J. Mar. Syst., 20(1-4), 83-112, 1999b.

Ovchinnikov, I. M.: On the water balance of the Mediterranean sea, Oceanology, Engl. Transl., 14, 198-202, 1974.

Sato, O. T., Polito, P. S., and Liu, W. T.: Importance of salinity measurements in the heat storage estimation from TOPEX/POSEIDON, Geophys. Res. Lett., 27, 4, 549-551, 2000.

Stammer, D.: Steric and wind-induced changes in TOPEX/POSEIDON large-scale sea surface topography, J. Geophys. Res., 102, C9, 20 987-21 011, 1997.

Stevenson, J. W. and Niiler, P. P.: Upper ocean heat budget during the Hawaii-to-Tahiti Shuttle experiment, J. Phys. Ocean., 13, 1894-1907, 1983.

Vivier, F., Kelly, K. A., and Thompson, L.: Contributions of wind forcing, waves, and surface heating to sea surface height observations in the Pacific Ocean, J. Geophys. Res., 104, C9, 20767 $20788,1999$.

Wang, L. and Koblinsky, C.: Can the Topex/Poseidon altimetry data be used to estimate air-sea heat flux in the North Atlantic?, Geophys. Res. Lett., 24, 2, 139-142, 1997. 